\title{
El conocimiento de la estructura textual: una estrategia clave que ayuda al alumnado de Educación Primaria en la comprensión de textos informativos
}

\author{
Marta PÉREZ DOMÍNGUEZ \\ Directora del CEIP "Santa Bárbara” \\ M $^{\mathrm{a}}$ Dolores RAÍDO BRAÑAS \\ Tutora de $3^{\circ}$ y $4^{\circ}$, CEIP "Santa Bárbara" \\ Miriam OVAlle TORRES \\ Tutora de $5^{\circ}$ y $6^{\circ}$, CEIP "Santa Bárbara" \\ Luis GONZÁLEZ SÁNCHEZ \\ Profesor de AL y E.F., CEIP "Santa Bárbara" \\ Esther CALERO PÉREZ \\ Profesora de Inglés, IES "Legio VII" \\ Ander PIEDRA GAMÍNDEZ \\ Profesor de Geografía e Historia, IES "Rosa Chacel” \\ Andrés CALERO \\ Psicopedagogo y Coordinador del Proyecto \\ acalero1@comprension-lectora.org
}

Recibido: 21 de septiembre de 2015

Aceptado: 3 de julio de 2016

\section{RESUMEN}

La compresión de textos informativos es esencial para el éxito académico del alumnado de Educación Primaria, y debería ser un importante foco de atención para el profesorado a raíz de la publicación del Currículo de Educación Primaria (RD 126/2014, de 28 de febrero). El presente trabajo describe un Proyecto de Innovación Pedagógica llevado a cabo en el CEIP "Santa Bárbara" de Matarrosa (León) durante el curso 2013/2014 con estudiantes de 3, 4, $5^{\circ}$ y $6^{\circ}$ de Educación Primaria, con el objetivo de desarrollar en ellos la conciencia de la estructura textual de los textos informativos, como una estrategia cognitiva clave de mejora de las destrezas de comprensión lectora. La estructura textual de los textos informativos 
supone un valioso sistema de señalización de pistas sintáctico-semánticas tanto dentro como fuera del texto, que nos informan sobre las conexiones lógicas que se establecen entre las ideas que contienen para facilitar su comprensión. Nuestros alumnos, entre 8 y 12 años, trabajaron a lo largo del curso escolar un conjunto de estrategias cognitivas y metacognitivas que les ayudaron a conocer y utilizar la variada estructura organizativa de los textos informativos (descripción, comparación/contraste, secuencia, causa/efecto, y problema/solución) para comprenderlos, recordarlos, y resumirlos por escrito. Al final del curso académico los estudiantes mejoraron significativamente: $a$ ) su habilidad para realizar una lectura estratégica, $b$ ) su destreza para escribir frases bien construidas con las estructuras textuales trabajadas, $c$ ) el conocimiento y uso de las palabras-clave que articulan la cohesión y la organización textual de las cinco estructuras trabajadas, $d$ ) su comprensión lectora, y la habilidad para resumir por escrito los diferentes textos leídos en clase, y $e$ ) su interés por la lectura de textos informativos.

Palabras clave: comprensión lectora, estrategias cognitivas, estrategias metacognitivas, textos informativos, currículo escolar, estructura textual, descripción, secuencia, comparación/contraste, causa/efecto, problema/solución.

\title{
Knowledge of text structure: A key cognitive strategy that helps primary students understand informational texts
}

\begin{abstract}
Comprehension of informational texts is essential to the academic success of every student in Primary Education, and it should be an important focus for teachers as a result of the publication of the new Primary School Curriculum (RD 126/2014, February-28th). In this paper, we will describe a Pedagogical Innovation Project carried out at the CEIP "Santa Bárbara" in Matarrosa (León) during the school year 2013/2014, with third, fourth, fifth and sixth grade elementary students. The aim was to develop their knowledge and use of the informational text structure as a key cognitive strategy that young readers have to activate in order for them to improve their reading comprehension skills. The informational text structure functions as a valuable syntactic and semantic cueing system both inside and outside the text, which informs the reader about the logical connections among its ideas, so that comprehension can be attained. Our students, aged 8 to 12, worked on a set of cognitive and metacognitive strategies throughout the school year, which helped them to understand better the meaning and use of the different types of informational texts (description, compare/contrast, sequence, causeleffect and problem/solution), to comprehend them, recall and produce written summaries of the texts read in the classroom. At the end of the academic year, the students showed significant improvement in: $a$ ) their ability to read strategically, $b$ ) their skill to produce well-structured written sentences with each of the five textual structures, $c$ ) the knowledge and use of the particular keywords that articulate the cohesion and textual organization of the five text structures they worked, $d$ ) their reading comprehension and the ability to write summaries of the different texts we read in class, and finally e) their interest in reading informational texts.
\end{abstract}

Key words: reading comprehension, cognitive strategies, metacognitive strategies, informational texts, curriculum, text structure, description, sequence, compare/contrast, cause/effect and problem/solution 


\section{La connaissance de la structure textuelle : une stratégie-clef qui aide l'élève}

\section{RÉSUMÉ}

de primaire à comprendre des textes informatifs

La compréhension des textes de nature informative est essentielle pour la réussite scolaire des élèves de primaire et devrait faire l'objet d'une attention particulière de la part du professorat, suite à la publication des programmes de l'enseignement primaire (Décret royal 126/2014, du 28 février). Ce travail décrit un projet d'innovation pédagogique mené à bien au CEIP (École maternelle et élémentaire) Santa Bárbara de Matarrosa (province de León) pendant l'année scolaire 2013-2014 avec des élèves de $3^{\mathrm{e}}, 4^{\mathrm{e}}, 5^{\mathrm{e}}$ et $6^{\mathrm{e}}$ années de primaire, dans le but de développer chez eux la connaissance et l'utilisation de la structure textuelle des textes informatifs, comme stratégie cognitive-clef afin d'améliorer leurs capacités de compréhension lectrice. La structure textuelle des textes informatifs représente un système précieux de signalisation des pistes syntactiques et sémantiques aussi bien dans le texte que hors de ce dernier, nous informant sur les connexions logiques qui s'établissent entre ses idées et facilitent sa compréhension. Nos élèves, âgés de 8 à 12 ans, ont travaillé tout au long de l'année scolaire sur un ensemble de stratégies cognitives et métacognitives qui les ont aidés à connaître et à utiliser la structure, variée et organisationnelle, des textes informatifs (description, comparaison/contraste, aspect séquentiel, causeleffet et problème/solution), pour les comprendre, s'en souvenir et les résumer par écrit. À la fin de l'année scolaire, les élèves ont fait des progrès significatifs dans : a) leur habileté à réaliser une lecture stratégique, b) leur aisance à écrire des phrases bien construites utilisant les structures textuelles travaillées, c) la connaissance et l'emploi des mots-clés qui articulent la cohésion et l'organisation textuelle des cinq structures travaillées, $d$ ) leur compréhension lectrice et leur habileté à résumer par écrit les différents textes lus en classe, et $e$ ) leur intérêt pour la lecture de textes informatifs.

Mots-clés : compréhension lectrice, stratégies cognitives, stratégies métacognitives, textes informatifs, programmes de l'enseignement primaire, structure textuelle, description, séquence, comparaison/contraste, cause/effet, problème/solution.

SUMARIO: 1. Los textos informativos y el desarrollo lector; 2. Fundamentos de nuestra Innovación Pedagógica; 2.1. El conocimiento de la estructura textual distingue a los lectores competentes de los que no lo son; 2.2. Los alumnos de Educación Primaria tienen escasas experiencias lectoras con los textos informativos; 2.3. El vigente Currículo de Educación Primaria y el conocimiento de las distintas estructuras textuales; 3. Nuestro Proyecto de Innovación Pedagógica; 3.1. Objetivos; 3.2. Alumnado; 3.3. Materiales de lectura en soporte papel y multimedia; 3.4. Proceso de instrucción y materiales de apoyo al aprendizaje de cada una de las estructuras textuales; 4. Evaluación del Proyecto; 5. Conclusiones; 6. Bibliografía. 
"Es la competencia con los textos informativos, no con los textos narrativos, la que más preocupa a los educadores y a los futuros empleadores"

(P. David Pearson)

\section{LOS TEXTOS INFORMATIVOS Y EL DESARROLLO LECTOR}

La instrucción directa en estrategias de comprensión lectora es una tarea a la que raramente se le presta una atención suficiente en las aulas de Educación Primaria (Calero, en prensa; Calero et al., en prensa) y, el escaso tiempo que a ello se le dedica, se destina esencialmente a la comprensión de textos narrativos, en detrimento de los de carácter expositivo. Estos últimos, más comúnmente denominados como textos informativos en el medio escolar, son especialmente más difíciles de comprender por los escolares de esa etapa educativa, porque su estructura textual y su contenido les resulta poco familiar. A diferencia de los textos narrativos, cuyo contenido se organiza en una secuencia temporal de hechos, los de carácter informativo ordenan y disponen sus ideas en diferentes y complejas estructuras con una relación lógica y abstracta entre ellas. Los textos informativos son aquellos que: a) tienen como propósito transmitir información sobre el mundo social y natural que nos rodea, $b$ ) están escritos con un lenguaje expositivo, c) contienen un vocabulario técnico, d) incluyen pistas textuales externas de naturaleza semántica (títulos, figuras, fotos, índices, tablas de contenidos, etc.), e) utilizan pistas textuales internas de índole morfo-semántica que cohesionan la organización de las ideas, entre ellas las denominadas palabras-clave que caracterizan sus distintas estructuras textuales ("a causa de", "en comparación con", etc.), f) emplean construcciones nominales genéricas ("los seres vivos, la agricultura ecológica", etc.), o verbales atemporales ("la Tierra gira alrededor del Sol"), y $g$ ) presentan la información en patrones o estructuras textuales específicas y variadas. En las figuras 1, 2 y 3 describimos las cinco estructuras textuales predominantes en los textos informativos que suelen utilizarse en las aulas de Educación Primaria (Meyer, 1975; Álvarez, 1996, Álvarez, 2013), con las palabras-clave que cohesionan e identifican la estructura textual concreta y los organizadores gráficos que hemos trabajados en este Proyecto de Innovación.

A pesar de las dificultades propias de lectura de estos textos, y del hecho de que en la escuela no es costumbre enseñar a los estudiantes a cómo comprenderlos, hoy sabemos que alumnos prelectores, o de los primeros cursos Educación Primaria, con unas prácticas pedagógicas adecuadas y textos auténticos, pueden llegar a establecer comparaciones, descripciones, o captar la noción de causalidad (Pappas, 1993; Duke \& Kays, 1998; Duke, 2014). Duke, (2014, 40), sugiere que no debemos esperar a que los estudiantes alcancen los últimos cursos de Educación Primaria para abordar estos aprendizajes formales, y propone que: $a$ ) tengan un acceso temprano a la lectura de textos informativos, $b$ ) se les aumente el tiempo que dedican a su lectura, $c$ ) se les 
enseñe de un modo explícito estrategias de comprensión lectora para comprenderlos, y $d$ ) se creen oportunidades para que el alumnado utilice los textos informativos en contextos pedagógicos significativos, como es el caso del aprendizaje basado en proyectos.

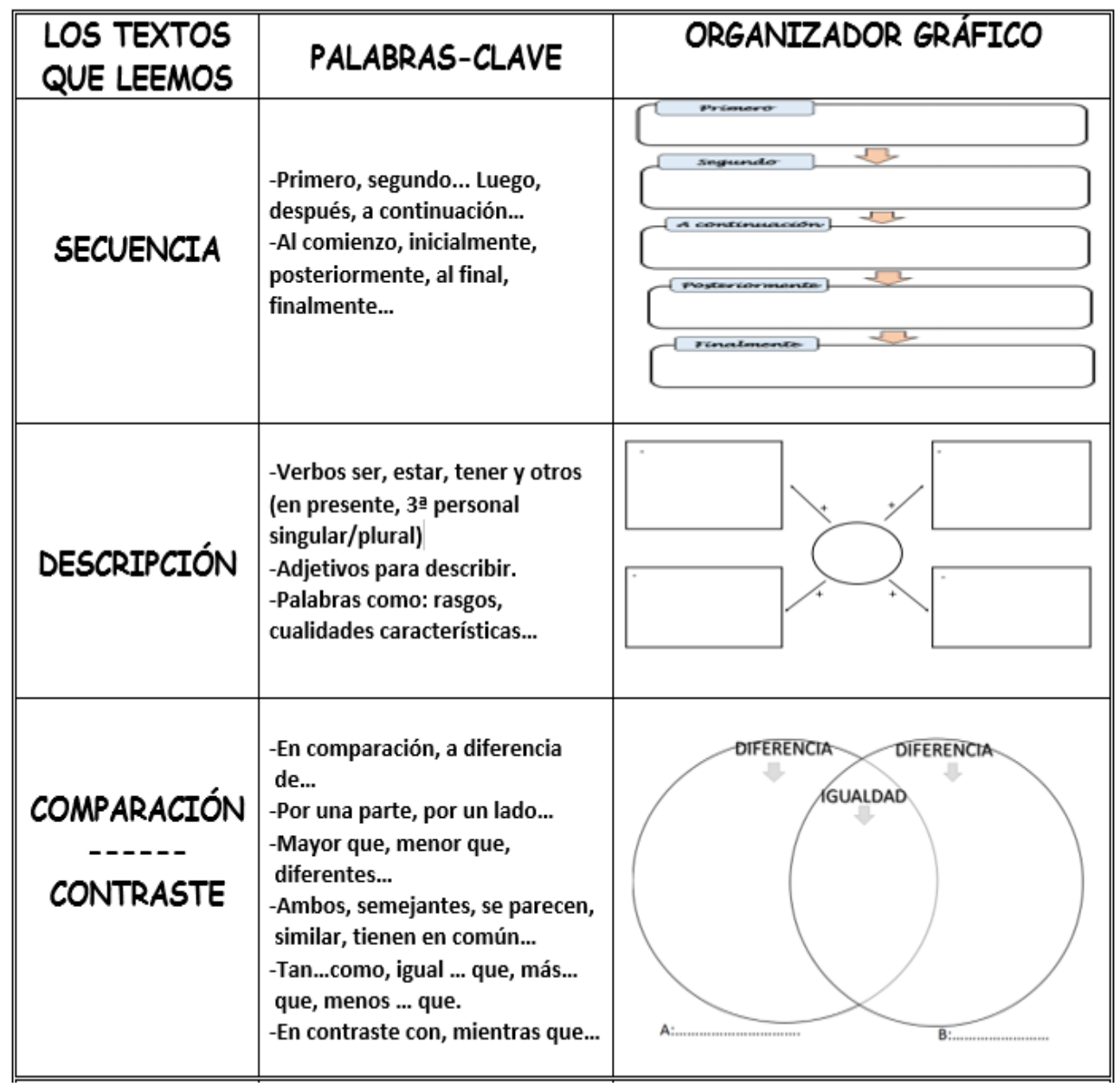

Figura 1. Estructuras textuales secuencia, descripción y comparación/contraste (CEIP "Santa Bárbara" / comprensión-lectora.org) 


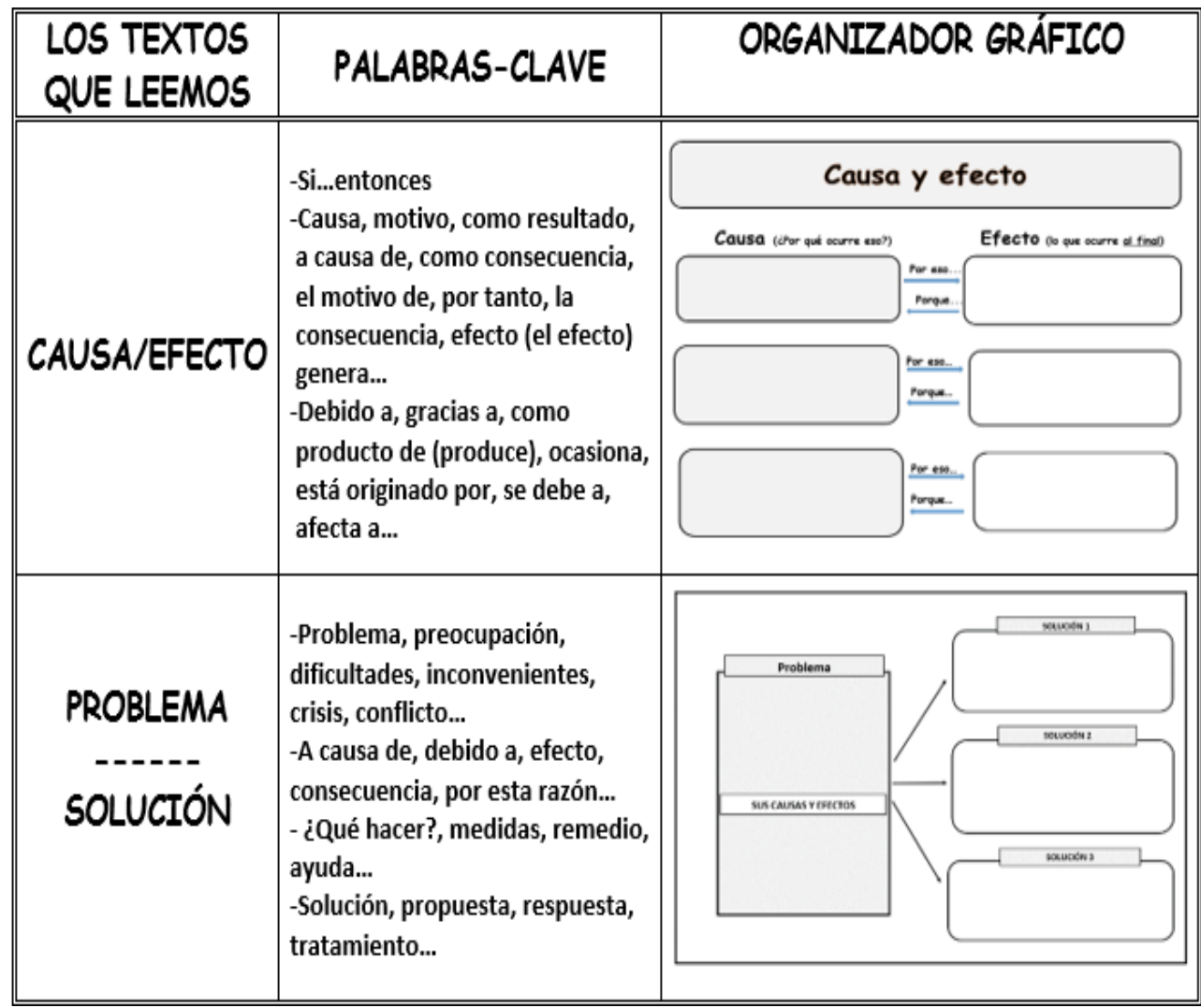

Figura 2. Estructuras textuales causa/efecto y problema/solución (CEIP "Santa Bárbara" / comprensión-lectora.org)

Ocurre, además, que en la sociedad de la información en la que vivimos (Garralón, 2013), los textos expositivos son predominantes, tanto en formato papel como electrónico: periódicos, revistas, blogs, formularios, prospectos, publicidad, textos divulgativos, científicos, etc. Un ejemplo, en la Web este tipo de textos supone aproximadamente el $90 \%$ del total de documentos publicados, y al final del curso $6^{\circ}$ de Educación Primaria más del $75 \%$ de la lectura y los exámenes que los alumnos realizan conlleva la comprensión de textos informativos. Asimismo, es un hecho que las pruebas diagnóstico que se aplican en las CC.AA. y en PIRLS ( $3^{\circ}$ y $4^{\circ}$ cursos) el $50 \%$ de los textos que se incluyen son informativos. Es, por tanto, una exigencia trabajar en esta etapa educativa la comprensión de estos textos, acomodando en las prácticas escolares de lectura la idea de que el desarrollo cognitivo, personal, la integración y el éxito de muchos estudiantes y adultos en el medio académico, laboral, y social, depende en gran medida de sus habilidades para comprenderlos. 


\section{FUNDAMENTOS DE NUESTRA INNOVACIÓN PEDAGÓGICA}

Tres son las evidencias en las que nuestro trabajo se apoya, desarrollado durante el curso 2013/14 por un grupo de profesores del CEIP "Santa Bárbara" de Matarrosa del Sil (León), con una muestra de alumnos de $3^{\circ}, 4^{\circ}, 5^{\circ}$ y $6^{\circ}$ de Educación Primaria: a) los datos que aporta la investigación educativa, que indican que el conocimiento y uso de la estructura textual de los textos informativos es una destreza que caracteriza a los buenos lectores, b) la constatación de que los estudiantes de esta etapa educativa tienen una exposición muy limitada a este tipo de textos, y c) la innovadora propuesta curricular escolar vigente (R.D. 126/2014, de 28 de febrero), que incluye una serie de estándares de aprendizaje que plantean la necesidad de que los lectores no solo aprendan a comprender textos narrativos, sino también expositivos.

\subsection{El conocimiento de la estructura textual distingue a los lectores competentes de los que no lo son.}

Leer es un proceso género-dependiente de construcción e integración de significado, en el sentido de que el género textual, el formato del texto, su estructura, es una variable importante que condiciona el modo de leer o escribir en la escuela. No se lee, no debe leerse, del mismo modo un texto que expone las causas/efectos de la lluvia ácida, que otro que narra una historia. Los datos que la investigación educativa aportan (Meyer, 1975; Meyer y otros, 2002; McNamara, 2004; Snyder \& Caccamine, 2010; Duke, 2014), plantean que la habilidad para reconocer y utilizar la estructura de los textos informativos es una estrategia singular que usan los buenos lectores para identificar las ideas principales de estos textos, para recordar más su contenido, y para producir por escrito textos de esta índole.

Sin embargo, es un hecho el que bastantes estudiantes de la educación básica poseen un escaso o nulo conocimiento y sensibilidad hacia la organización textual externa e interna de los materiales de lectura con los que trabajan. En particular, muestran un limitado conocimiento de las diferencias entre la estructura narrativa y la propia de los textos expositivos más variada y compleja. Si tenemos en cuenta que leer supone un escenario de construcción e integración de significado, en el que se da una transacción entre los procesos cognitivos y metacognitivos (estrategias) que el lector pone en juego en la tarea, y el específico género textual del libro que lea, el conocimiento que ese lector posea de la particular conformación estructural del contenido del texto (narrativa, expositiva, poética, etc.), condicionará y determinará el tipo de estrategias que utilice para comprenderlo, y su logro en comprensión lectora. De otro modo, la comprensión se da cuando las destrezas estratégicas que aporta el lector conciertan y negocian las características lingüísticas y organizativas del texto (Escoriza, 2006; Snyder, 2010; Duke, 2014; García et al., 2015). 


\begin{tabular}{|c|c|l|}
\hline ESTRUCTURA & \multicolumn{1}{|c|}{ DESCRIPCIÓN } & \multicolumn{1}{c|}{ EJEMPLOS } \\
\hline SECUENCIA/ORDEN & $\begin{array}{l}\text {-El proceso de cuándo o en qué orden } \\
\text { ocurren las cosas o acciones a realizar. }\end{array}$ & $\begin{array}{l}\text {-Cómo construir un huerto escolar } \\
\text {-Cómo se forman las tormentas }\end{array}$ \\
\hline DESCRIPCIÓN & $\begin{array}{l}\text {-Lo que alguien o algo es, parece, o está } \\
\text { compuesto de. }\end{array}$ & $\begin{array}{l}\text {-Características fisicas de una comarca } \\
\text {-El hábitat y las costumbres de determinados } \\
\text { animales }\end{array}$ \\
\hline COMPARACIÓN/CONTRASTE & $\begin{array}{l}\text {-Cómo se parecen o diferencias las cosas, } \\
\text { personas o animales. }\end{array}$ & $\begin{array}{l}\text {-Diferencias entre tornados y los huracanes } \\
\text {-El hábitat urbano y rural }\end{array}$ \\
\hline CAUSA/EFECTO & -Cómo un suceso conduce a otro & $\begin{array}{l}\text {-La lluvia ácida y la agricultura } \\
\text {-Las consecuencias del tabaco }\end{array}$ \\
\hline PROBLEMA/SOLUCIÓN & -Las causas, sus efectos y las soluciones & $\begin{array}{l}\text {-Los efectos de la inundaciones y cómo } \\
\text { prevenirlas. } \\
\text {-Los recursos alimentarios y el hambre en el } \\
\text { mundo. }\end{array}$ \\
\hline
\end{tabular}

Figura 3. Descripción y ejemplos de las estructuras textuales de carácter informativo

Por tanto, la comprensión de los textos informativos exige del estudiante una atención dirigida a descubrir las pistas semánticas que desvelan su estructura para, por ejemplo, conseguir entender cómo en uno se establece una secuencia a seguir para construir un electroimán, y en otro una relación causa/efecto que informe sobre las consecuencias del enfriamiento de la Tierra en el clima. Si ese conocimiento no se aprende, el alumnado de los cursos intermedios de Educación Primaria experimenta lo que viene en denominarse el "declive de $4^{\circ}$ curso" (fourth-grade slump) (Chall, 1996; Sanacore, 2009), que se manifiesta por la inhabilidad que tienen para entender esos textos de Ciencias Naturales, Ciencias Sociales, Matemáticas, etc., que ahora empiezan a "leer para comprenderlos", y "aprender" su contenido, perdiéndose entre las palabras que leen, e incapaces de "ver" y manejar la organización de las ideas de esas nuevas lecturas.

Una instrucción directa en el desarrollo de la conciencia de la estructura textual tiene un efecto positivo en la comprensión lectora (Pearson y Duke, 2002; McNamara, 2004; Kendra y otros 2005; Dymock, 2009). Así, en un estudio de entrenamiento llevado a cabo por Kendra y otros (2005), se investigó el efecto de un programa de instrucción directa en estrategias de conocimiento y uso de la estructura expositiva comparación/contraste, sobre el nivel de comprensión lectora de una muestra de 72 estudiantes de $2^{\circ}$ curso de Educación Primaria. Tras seis semanas de aplicación del programa, sus resultados evidenciaron que el grupo experimental "Instrucción en Estructura de Textos Informativos" obtuvo puntuaciones significativamente más altas que otros dos grupos de control, en pruebas de resumir 
un texto, recuerdo de palabras-clave, uso de organizadores gráficos y vocabulario. Los autores concluyen afirmando:

Los resultados del estudio, sugieren que la instrucción en desarrollo de la conciencia de la estructura de textos comparación/contraste es una estrategia efectiva para mejorar la comprensión lectora del alumnado de $2^{\circ}$ grado. Aquellos lectores que recibieron el entrenamiento, fueron capaces de usar de un modo efectivo estrategias tales como el manejo de palabras-clave y organizadores gráficos, ganaron un conocimiento conceptual sobre los textos de este tipo, y fueron capaces de producir resúmenes escritos bien estructurados, a diferencia de aquellos otros que no lo recibieron (Kendra, 2005, 220).

Asimismo, hoy sabemos que los prelectores y los lectores jóvenes pueden aprender los registros lingüísticos característicos de las distintas estructuras de los textos informativos, siempre que tengan un contacto regular con estos materiales de lectura (Pappas, 1993; Hicks, 1995; Caswell \& Duke, 1998; Duke \& Kays, 1998). Por ejemplo, Hicks (1995) documentó cómo alumnos de una clase de primer curso eran capaces de generar oralmente y por escrito frases propias de estructuras expositivas ("Los bomberos luchan contra el fuego", en lugar de "los bomberos están apagando un incendio"), en una situación en la que se les leía regularmente libros informativos en voz alta. En este mismo sentido, los trabajos de Pappas (1993) y de Duke \& Kays (1998) describen cómo prelectores acostumbrados a que sus profesores les leyeran habitualmente en voz alta textos expositivos, fingían también leerlos respetando sus rasgos estructurales específicos, por ejemplo, repitiendo secuencias como "en primer lugar... en segundo lugar...", etc.

\subsection{Los alumnos de Educación Primaria tienen escasas experiencias lectoras con los textos informativos}

¿Están las bibliotecas escolares y las de aula dotadas de suficientes libros informativos? ¿Se dedica tiempo escolar a su lectura? Varios estudios descriptivos muestran que eso no ocurre (Duke, 2000a, 2000b; Yopp \& Yopp, 2006). Nell Duke (2000a), llevó a cabo un trabajo en 20 escuelas de primero de Educación Primaria, constatando que existen graves carencias de dotación de materiales y de experiencias de lectura con este tipo de textos. Eligió 10 aulas situadas en barrios de nivel socioeconómico bajo y otras 10 de nivel socioeconómico alto, planteándose un doble objetivo de investigación: $a$ ) conocer el tipo de materiales de lectura de que disponían las bibliotecas de esas aulas, y $b$ ) averiguar el tiempo dedicado a trabajar con textos informativos. Tras visitar cuatro veces a jornada escolar completa cada una de las aulas, los datos que esta investigadora obtiene confirman la escasez de materiales de naturaleza informativa disponibles en las bibliotecas de aula (ver figura 4). Mientras que los desplegados en las aulas de los distritos de nivel socioeconómico alto suponía un $12,7 \%$ del total, solo un 6,9\% de ellos formaban parte de las bibliotecas que pertenecían a las aulas de los distritos de nivel socioeconómico bajo. Con respecto al 
tiempo de exposición de los alumnos a actividades de lectoescritura con textos informativos, Duke llevó a cabo 79 días de observaciones concluyendo que en las aulas de nivel socioeconómico alto se destinaron durante ese tiempo solo 282 minutos (media de 3,6 minutos al día). Peor aún, en las aulas pertenecientes a distritos de bajo nivel socioeconómico, ese tiempo disminuía a 1,4 minutos por día (ver tabla 1). Y, lo que es más dramático, 7 de las 20 aulas no realizaron actividad alguna con esos textos.

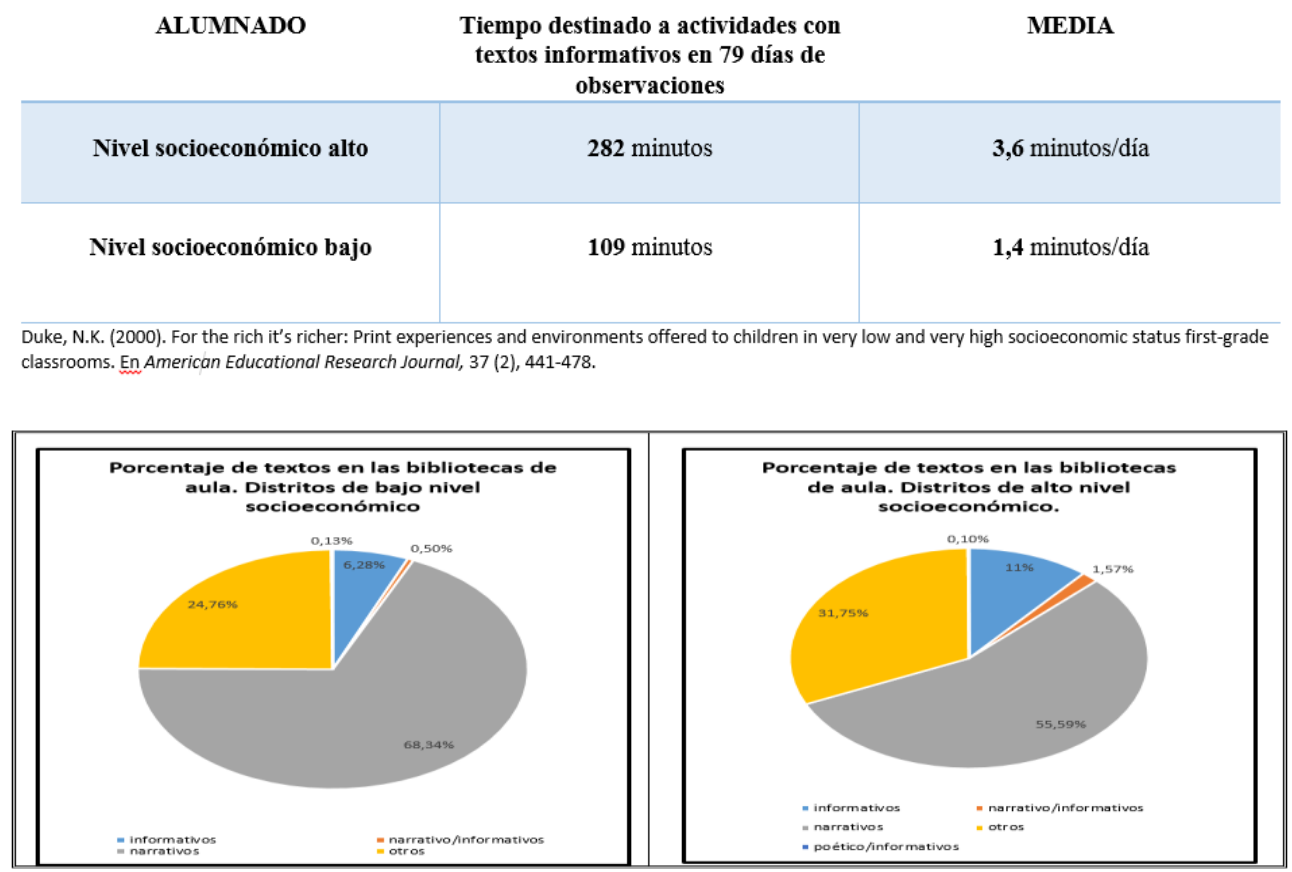

Figura 4 y tabla 1. Adaptado de Duke (2000b). Datos en media de porcentajes del tipo de libros que contenían las bibliotecas de las aulas, y tiempo destinado a actividades de lectoescritura con textos informativos en colegios pertenecientes a distritos de niveles socioeconómicos bajo y alto

\subsection{El vigente Currículo de Educación Primaria y el conocimiento de las distintas estructuras textuales}

Una de las novedades del vigente Currículo Básico de Educación Primaria es el establecimiento de estándares, o metas de aprendizaje que el alumnado debe alcanzar al acabar esta etapa educativa, como indicadores de logro expresados en términos de procesos estratégicos. Estos estándares representan una importante innovación con respecto a currículos anteriores, al indicar la necesidad de estimular el pensamiento estratégico del alumnado para comprender los distintos textos escolares: "Comprender un texto implica poner en marcha una serie de estrategias de lectura 
que deben practicarse en el aula y proyectarse en todas las esferas de la vida y en todo tipo de lecturas: leer para obtener información, leer por placer..." (RD, 19379).

Asimismo, en el citado RD se aboga por una dieta equilibrada de lectura, señalando el objetivo de utilizar textos de distintos géneros en las prácticas de aprendizaje de la comprensión lectora: "La adquisición de la destreza lectora solo puede conseguirse a través de la lectura de distintas clases de textos, de su comprensión y de la reflexión sobre ellos" (Anexo I, 19378). Más concretamente, en el Currículo se prioriza: a) la enseñanza de destrezas estratégicas de alfabetización con textos informativos, en concreto aquellas referidas al conocimiento de su estructura externa e interna (ver figura 5); y b) el contacto del estudiante con textos de diversos géneros, en orden a mejorar su competencia lectora. Así, de los 46 estándares de aprendizaje que se relacionan en los bloques 2 y 3 , en el 41,3\% de ellos se hace referencia expresa al uso de "textos de distinta índole", "diferentes tipos de texto", "diferentes géneros literarios", etc..., y en ellos se define la necesidad de que los estudiantes aprendan estrategias de comprensión lectora propias de este tipo de textos. También, si observamos el bloque 2. "Comprensión escrita: Leer", de los 29 estándares que se incluyen, 8 de ellos (el 27\%) invitan al conocimiento y al manejo de aquellos elementos que pueden caracterizar la estructura textual externa e interna de las dos tipologías de textos que más frecuentemente se trabajan en Educación Primaria: los textos narrativos y los expositivos (específicamente los estándares 2.24.1-4.2-4.3-5.1-5.2-8.2-8.4).

De acuerdo con todo lo anterior, en nuestro Proyecto de Innovación apostamos decididamente por instruir al alumnado en el conocimiento y uso de la estructura textual de los textos informativos para:

- Proporcionarles un instrumento cognitivo de desarrollo lector y académico (Pappas, 1993).

- Apoyar la opción lectora de muchos niños y niñas ("estudiantes info") que eligen leer textos informativos. Respetarla y estimularla es una responsabilidad de la escuela. Para los demás estudiantes, facilitarles experiencias lectoras con esos textos puede incrementar su interés por ellos, como catalizadores de su desarrollo lector general (Duke, 2014).

- Aumentar su nivel de vocabulario académico, como un recurso lingüístico/cognitivo que potencia su capacidad de comprensión lectora (Nagy, 2005).

- Mejorar sus esquemas de conocimiento sobre el mundo social y natural (Anderson, 1984). Cuantos más conocimientos previos puedan almacenar más competentes llegarán a ser como lectores. 


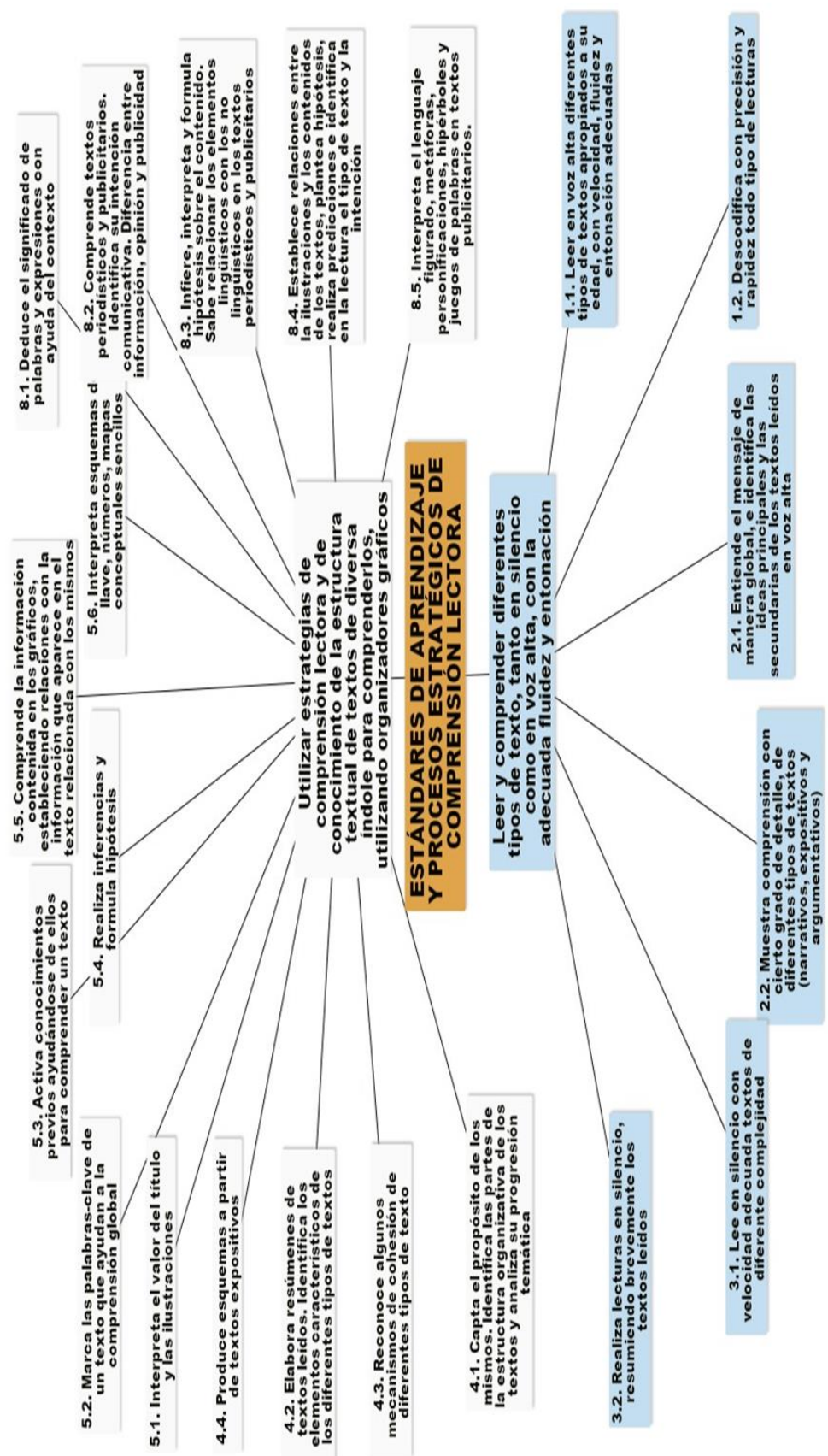

Figura 5. Estándares de aprendizaje Lengua Castellana y Literatura. Bloque 2. Comunicación escrita: Leer 
- Dar respuesta a sus necesidades de conocimiento, a sus preguntas, y a su interés por estos textos, impulsando así su motivación por leerlos (Yopp \& Yopp, 2006).

\section{NUESTRO PROYECTO DE INNOVACIÓN PEDAGÓGICA}

\subsection{Objetivos}

Dos fueron los objetivos básicos que nos plantemos para llevar a cabo este proyecto: $a$ ) evaluar la incidencia de un programa de instrucción en el conocimiento y uso de la estructura textual de textos informativos sobre la conducta lectora estratégica general de 14 estudiantes, y $b$ ) llevar a cabo para ello el diseño de un estudio descriptivo de investigación pre-experimental de grupo único con pretest / postest. Se trabajaron cinco estructuras textuales expositivas: descripción, causa / efecto, secuencia, comparación / contraste y problema / solución.

\subsection{Alumnado}

El Colegio Santa Bárbara está situado en Matarrosa del Sil, una localidad minera del municipio de Toreno (León). Los 14 estudiantes que participaron en el Programa se dividieron en dos grupos: Un grupo $A$ formado por 7 estudiantes de los cursos tercero (4 alumnos), y cuarto (3 alumnos), y un grupo $B$ formado por otros 7 estudiantes, de los cuales 4 pertenecían a quinto y 3 al sexto curso. Dos estudiantes estaban repitiendo curso, uno en cuarto y otro en sexto. Además, uno de tercero, otro de cuarto, y una alumna de sexto, recibían apoyo de Audición y Lenguaje, junto con otro de quinto que tenía un diagnóstico de TDH.

\subsection{Materiales de lectura en soporte papel y multimedia}

Para el desarrollo del trabajo, dispusimos de una amplia variedad de materiales de lectura. Por una parte, señalar que durante el curso escolar 2013/14 las maestras del Colegio "Santa Bárbara" se plantearon la mejora lectora del alumnado creando distintos espacios de lectura, juego e imaginación, que invitaban a leer sobre la temática del Proyecto Anual para ese curso escolar: "El Espacio". En una zona idónea, se construyó una "nave espacial" de 8 metros cuadrados de base y 2,20m de altura con la ayuda del AMPA, un rincón de lectura dotado mayoritariamente con textos informativos sobre el Espacio, adonde los tutores llevaban a sus alumnos a realizar tareas de lectura en voz alta, compartida, e independiente. El sistema de aprovisionamiento de libros provino de: a) una dotación económica derivada de la participación en una convocatoria para la obtención de ayudas para Bibliotecas Escolares, $b$ ) ejemplares prestados por el Servicio del Bibliobús $\mathrm{n}^{\circ} 5$ del Instituto Leonés de Cultura (Diputación de León), y $c$ ) ejemplares prestados por el profesorado $\mathrm{y}$ familias. Asimismo, se adquirieron muestras de distintos textos informativos que el mercado editorial ofrece, con una temática variada como: los animales, el planeta 
Tierra, la Prehistoria, los transportes, el agua, la ecología, las pirámides de Egipto, etc. Se buscó en ellos que fueran textos cortos, que se adecuaran a las cinco estructuras textuales que se iban a trabajar, y que cuidaran la inclusión de elementos textuales externos (índice, glosario, contraportada, tabla de contenidos, y pistas gráficas apropiadas como dibujos, fotos, tablas, etc.), e internos (uso de nexos, o palabras-clave, que relacionaran y cohesionaran las ideas del texto. También, se emplearon otros materiales de lectura propios de los libros de texto de Ciencias de la Naturaleza y Ciencias Sociales utilizados durante el curso escolar, junto con diferentes revistas infantiles como "Muy Interesante Junior", "Leo, leo" y "Boing", $\mathrm{y}$ otros contenidos de distintas páginas Webs.

Como materiales de apoyo a la comprensión lectora, y a la clarificación y la utilización de las distintas estructuras textuales que se trabajaron, decidimos crear: a) murales, b) palabras-clave plastificadas de cada estructura, y c) organizadores gráficos para que los alumnos los usaran como soportes visuales durante la presentación, manipulación y ordenación en ellos de las ideas que en los textos se exponían. Del mismo modo, en orden a facilitar el autoaprendizaje del estudiante, el equipo de profesores creó una Aplicación a través del editor de actividades EdiLim, un visualizador (LIM) y un archivo en formato XML del sistema Lim. Se trata de un entorno para la construcción de materiales educativos, fácil de usar por los alumnos y el profesorado, con posibilidades de utilización en ordenadores, PDA's y pizarras digitales interactivas, que ofrece al alumnado el control personal del conocimiento y la autoevaluación que se generó con cada una de las cinco estructuras textuales (ver figura 6). Finalmente, en una sesión con todo el grupo de alumnos grabamos un video en el que los estudiantes expusieron el conocimiento metacognitiva adquirido al final del curso, en una actividad de reflexión en voz alta sobre las estrategias trabajadas.

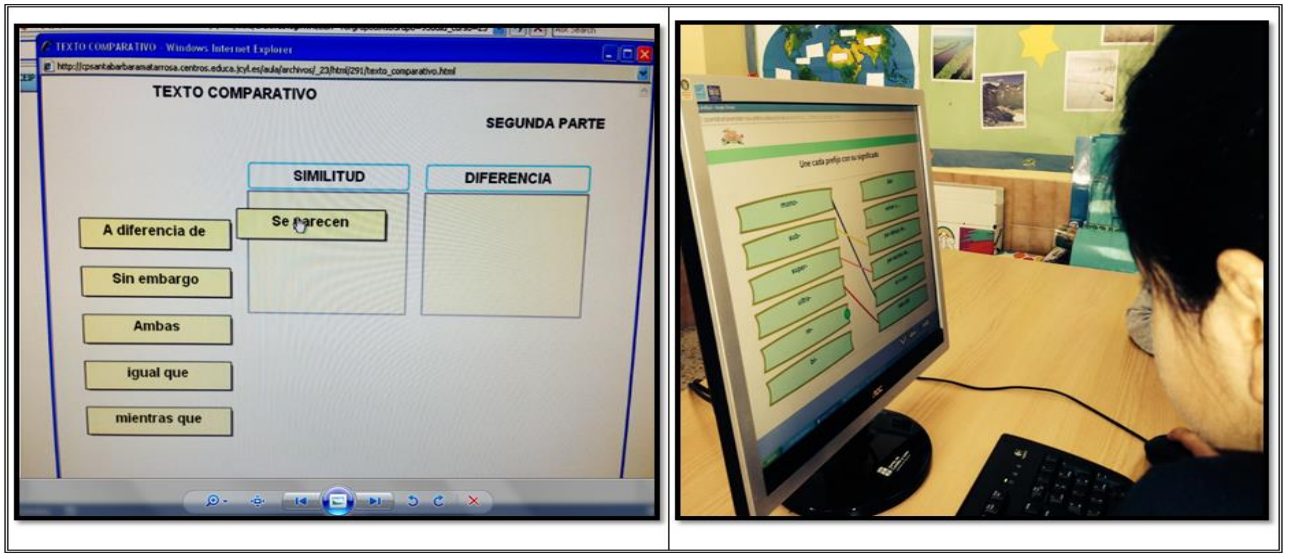

Figura 6: Actividades online con textos comparativos (CEIP "Santa Bárbara” /comprensiónlectora.org) 


\subsection{Proceso de instrucción y materiales de apoyo al aprendizaje de cada una de las estructuras textuales}

En el diagrama de la figura 7 representamos, en sentido contrario a las agujas del reloj, el mapa de procesos de pensamiento estratégico que trabajamos para despertar en el alumnado la conciencia de la estructura textual de los textos leídos, en este orden: a) presentación de cada una de las cinco estructuras textuales, b) reconocimiento y uso de las pistas semánticas de la estructura externas del texto, c) reconocimiento y uso de las pistas semánticas de la estructura interna del texto, y d) estrategias cognitivas y metacognitivas a utilizar.

Durante el mes de septiembre, llevamos a cabo una evaluación inicial para conocer: a) el nivel de conciencia de lectura estratégica que nuestros alumnos poseían antes, durante y después de leer un texto, medido a través de un cuestionario, y b) su capacidad para producir por escrito frases bien estructuradas de tres tipos de textos informativos: relación causa/efecto, comparación/contraste y secuencia, medida con una prueba en la que los estudiantes utilizaron apoyaturas visuales para la ejecución de la tarea. Igualmente, seleccionamos textos informativos apropiados para cada estructura, que resaltaran un único e identificable patrón de organización textual, con el objetivo de facilitar al estudiante su conocimiento. Buscábamos, además, que los textos presentaran un alto grado de cohesión interna incluyendo las palabras-clave más usuales del tipo de estructura que se trabajara. Otros materiales de apoyo fueron:

1. Los murales en formato cartulina $\mathrm{A} 2$, que se utilizaron como apoyatura gráfico-visual para clarificar el sentido de cada una de las cinco estructuras textuales. Los alumnos disponían de una copia en formato A4.

2. Los organizadores gráficos, como refuerzos visuales para aprender a ordenar por escrito en ellos la información y las ideas principales de los distintos textos informativos trabajados, Los alumnos usaban una copia en formato A4 (ver figura 8).

3. La aplicación informática del sistema Lim, para facilitar a los estudiantes el autoaprendizaje de cada estructura textual y sus palabras-clave, en actividades que llevaron a cabo en la Sala de Ordenadores, en la pizarra digital, o en trabajo independiente en su domicilio (ver figura 6).

Con cada estructura textual seguimos una secuencia de instrucción en la que las cuatro primeras tareas eran responsabilidad del docente, y las dos siguientes de los alumnos en trabajo de equipo e individualmente: 


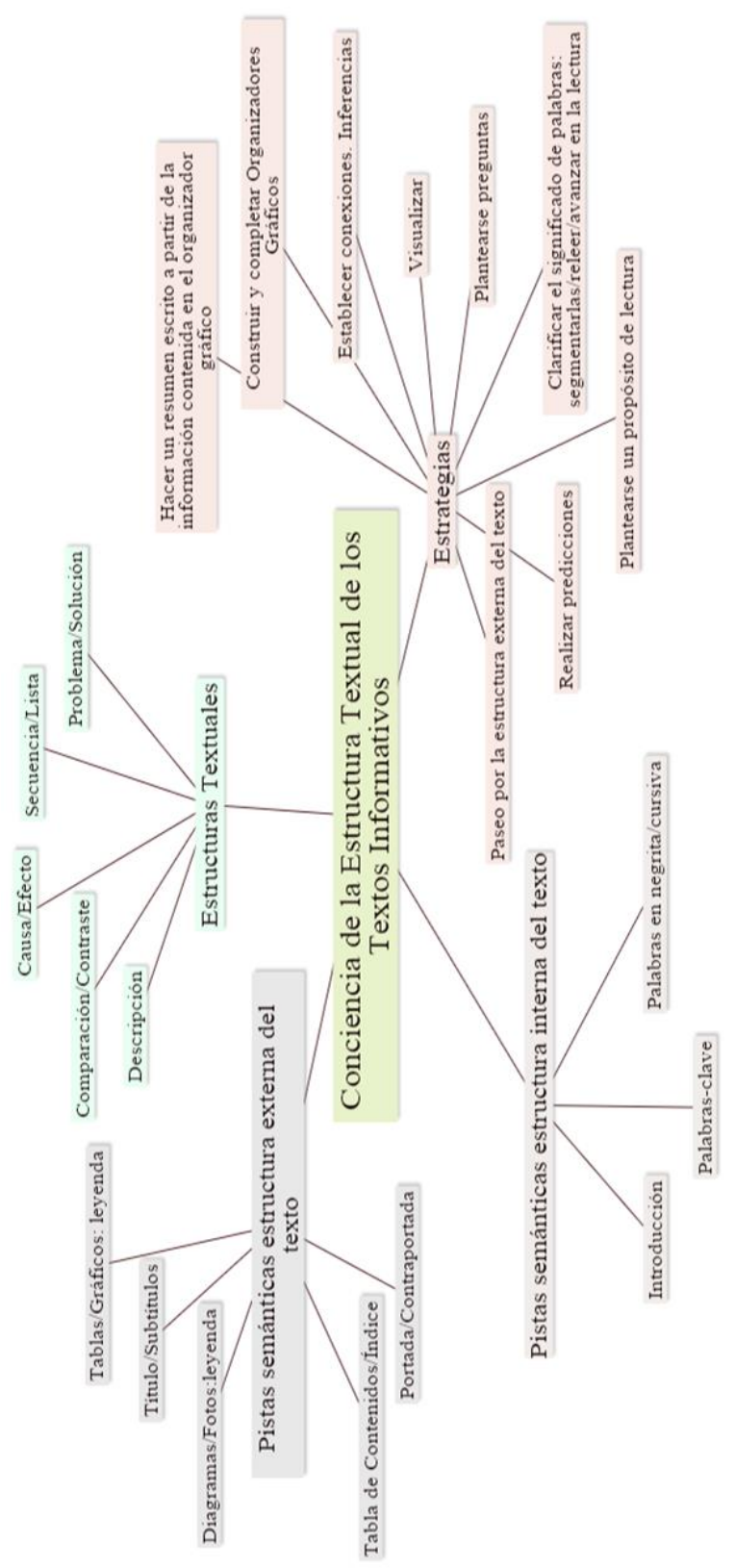

Figura 7. Mapa conceptual de los procesos de pensamiento estratégico que se trabajaron con los alumnos 


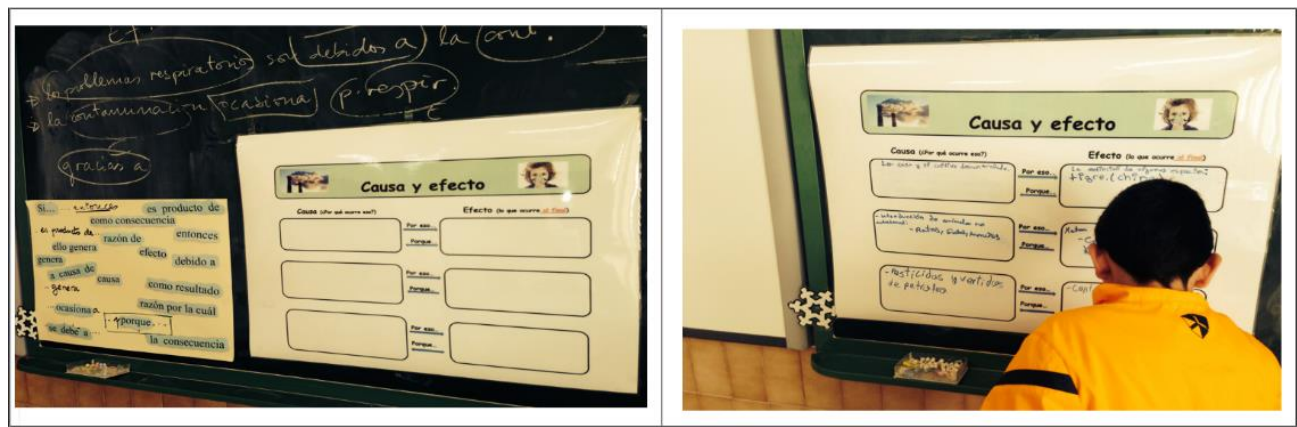

Figura 8. Palabras-clave y organizador gráfico para ordenar las ideas principales de la estructura textual causa/efecto (CEIP "Santa Bárbara" / comprensión-lectora.org)

- Presentación de palabras-clave plastificadas y adhesivas. Con cada estructura, el docente compartía con los estudiantes la idea de que los autores incluyen determinadas palabras-clave en los textos para caracterizarlos y servir de nexo entre las ideas más importantes que quieren transmitir. Se les motivó a jugar a ser detectives para encontrarlas. Tras esa presentación, cada alumno elegía una palabra-clave, pensaba en una frase que la incluyera, la colocaba sobre el organizador gráfico, y revelaba finalmente al grupo-clase la frase que había inventado.

- Primera lectura y clarificación de la estructura textual. El profesor leía un texto corto y, reflexionando en voz alta, se detenía cuando descubría una palabra-clave, la subrayaba y desvelaba la función de nexo que ejercía entre las ideas contenidas en el texto, revelando qué tipo de estructura textual era: bien de comparación/contraste, secuencia, problema/solución, etc.

- Uso de los organizadores gráficos. En esta fase de modelado, el docente colocaba el organizador gráfico en la pizarra o lo proyectaba en la pizarra digital para así desvelar con su pensamiento cómo completarlo con las ideas principales que el texto contenía (ver figura 8).

- Resumen del texto. A continuación, el profesor modelaba frente a los alumnos cómo a partir de las ideas incluidas en el organizador gráfico se confeccionaba una síntesis escrita del texto leído sobre una pauta-resumen, que fue diseñada para orientar la producción de resúmenes bien estructurados. Esta pauta contenía frases introductorias para cada tipo de estructura textual, que guiaban la organización de las ideas principales y una opinión personal (ver figura 9).

- Trabajo por equipos. Cada equipo disponía de un texto y un organizador gráfico con las siguientes instrucciones: a) leer el texto subrayando las palabras-clave, $b$ ) decidir cómo rellenar el organizador gráfico con las ideas principales, y c) convenir un resumen escrito del mismo, que se completaba en la pauta-resumen con las ideas recogidas en el organizador gráfico y una opinión acordada. Dicho resumen se exponía posteriormente al grupo-clase. 
- Trabajo individual. Los estudiantes leían un texto, rellenaban el organizador gráfico, y completaban su resumen en la pauta correspondiente.

Los resúmenes de aquellos alumnos que lo desearan se compartían con el resto de la clase.

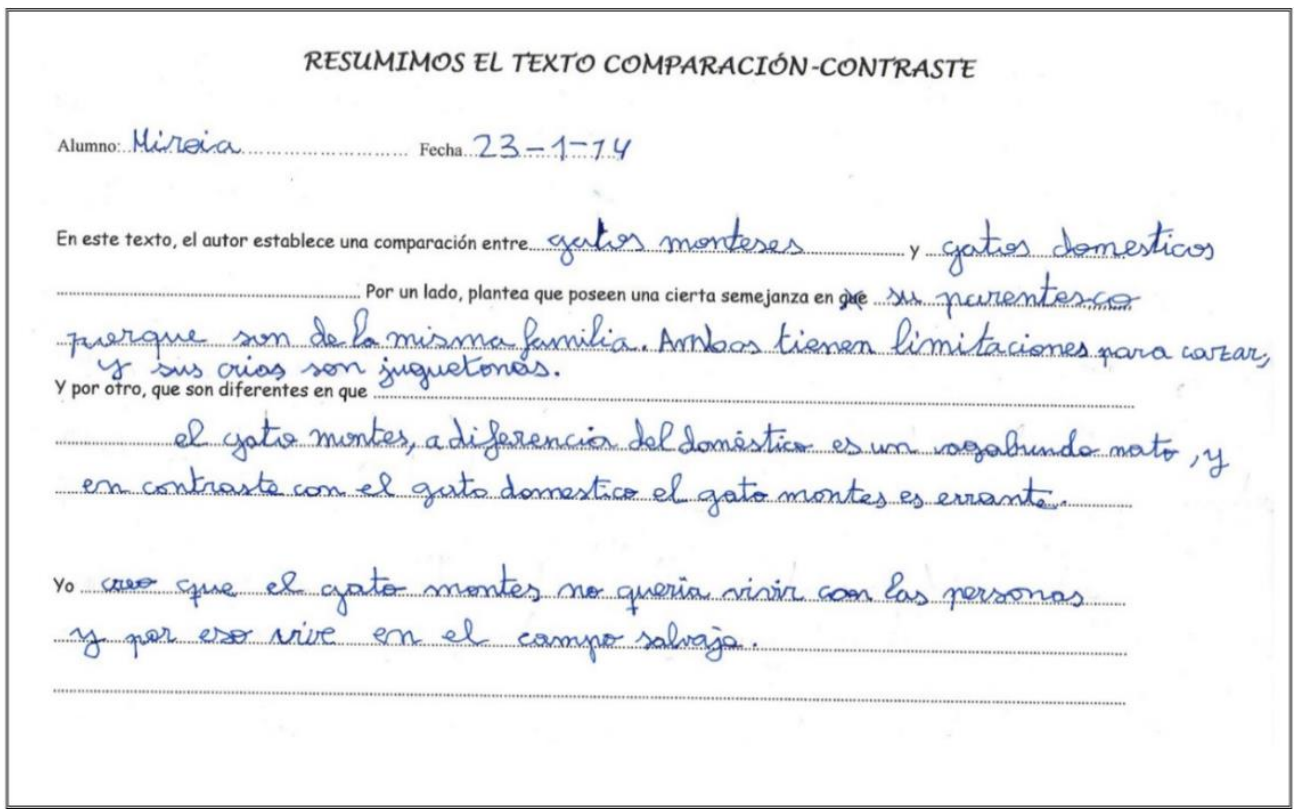

Figura 9. Pauta-resumen para resumir un texto de comparación/contraste

\section{EVALUACIÓN DEL PROYECTO}

En junio-2014, evaluamos y analizamos cinco variables del Proyecto:

a) El nivel de logro en conocimiento de procesos de pensamiento estratégico básicos de comprensión lectora (predecir, clarificar el significado de palabras, etc.), a través de un estudio descriptivo preexperimental intrasujeto, con un diseño pretest/postest de grupo único, medido por la prueba de Conciencia de Lectura Estratégica (ver figura 10).

b) La habilidad de nuestros estudiantes para expresar por escrito frases bien construidas, con una apoyatura visual de dibujos que aludían a cada estructura textual. Para ello, aplicamos la prueba de Escritura de Frases bien Estructuradas. En ella, seguimos el criterio de que en cada una de las frases los alumnos debían incluir al menos una palabra-clave que definiera la situación que gráficamente se les presentaba, con tres estructuras textuales: comparación/contraste, causa/efecto y secuencia. 


\begin{tabular}{|c|c|}
\hline PREGUNTAS & RESPUESTAS \\
\hline $\begin{array}{l}\text { 3. Ahora, cuando estás leyendo el } \\
\text { libro, ¿qué sueles pensar o } \\
\text { hacer? } \\
\text { Elige otra vez } 3 \text { respuestas que } \\
\text { crees son las más acertadas, } \\
\text { redondeando la letra } \\
\text { correspondiente: }\end{array}$ & $\begin{array}{l}\text { a) Me preocupo por no confundirme al leer palabras } \\
\text { b) Pienso si mis predicciones que hice antes de leer se confirman o } \\
\text { no. } \\
\text { c) No miro los dibujos, porque pueden confundirme al leer. } \\
\text { d) Compruebo cuántas páginas me faltan por leer. } \\
\text { e) Me ayudo de las palabras escritas en negrita o cursiva para * } \\
\text { comprender el texto. } \\
\text { f) Me paro de vez en cuando para preguntarme si estoy } \\
\text { comprendiendo. }\end{array}$ \\
\hline $\begin{array}{l}\text { 4. También, cuando estás } \\
\text { leyendo, ¿qué más haces? } \\
\text { Elige de nuevo } 3 \text { respuestas } \\
\text { que crees son las más } \\
\text { acertadas, } \\
\text { redondeando la letra } \\
\text { correspondiente: }\end{array}$ & $\begin{array}{l}\text { a) Procuro leer todas las palabras correctamente. } \\
\text { b) Si me encuentro con palabras como: similar, semejante, del } \\
\text { mismo modo, o "por el contrario", pienso que el autor está } \\
\text { haciendo una comparación. } \\
\text { c) Leer despacio y tener cuidado de no saltarme ninguna } \\
\text { página. } \\
\text { d) Cuando encuentro una palabra desconocida, me fijo en las } \\
\text { palabras cercanas para descubrir su significado. } \\
\text { e) Comprobar cuántas páginas me faltan por leer. } \\
\text { f) Suelo predecir palabras que vienen después en el texto. Así, } \\
\text { cuando el autor escribe la palabra "primero", más abajo } \\
\text { seguro que va a poner la palabra "segundo" y "tercero". * }\end{array}$ \\
\hline
\end{tabular}

Figura 10. Fragmento del Cuestionario de Evaluación de Lectura Estratégica

c) La capacidad de los estudiantes para reconocer y diferenciar las cinco estructuras textuales trabajadas durante el curso escolar, leyendo cinco textos cortos (ver ejemplo, figura 11).

d) Sus preferencias de lecturas, evaluada a través de la elección personal de un libro, de entre una muestra de tres de naturaleza narrativa, y otros tres de carácter informativo, valorándose además los procesos de pensamiento aportados en la elección de unos libros sobre otros.

e) El conocimiento metacognitivo que mostraba el grupo de alumnos acerca de las estrategias que utilizaron para aprender a comprender textos informativos, mediante una puesta en común con todo el grupo, que fue grabada en video.

En relación a la prueba de Lectura Estratégica, el gráfico de barras de la figura 12 y la tabla 2 nos muestran que, tras el periodo de instrucción, los estudiantes obtuvieran una mayor puntuación en el postest que en el pretest. Dos pruebas no paramétricas utilizadas (Wilcoxon-Mann-Whitney, y Kruskal- Wallis) confirmaron una diferencia significativa entre los resultados pretest/postest: $W=9.5$, $p=4.754 e-05 ; K-W$ chi-cuadrado $=27, d f=11, p=0.004595$. 


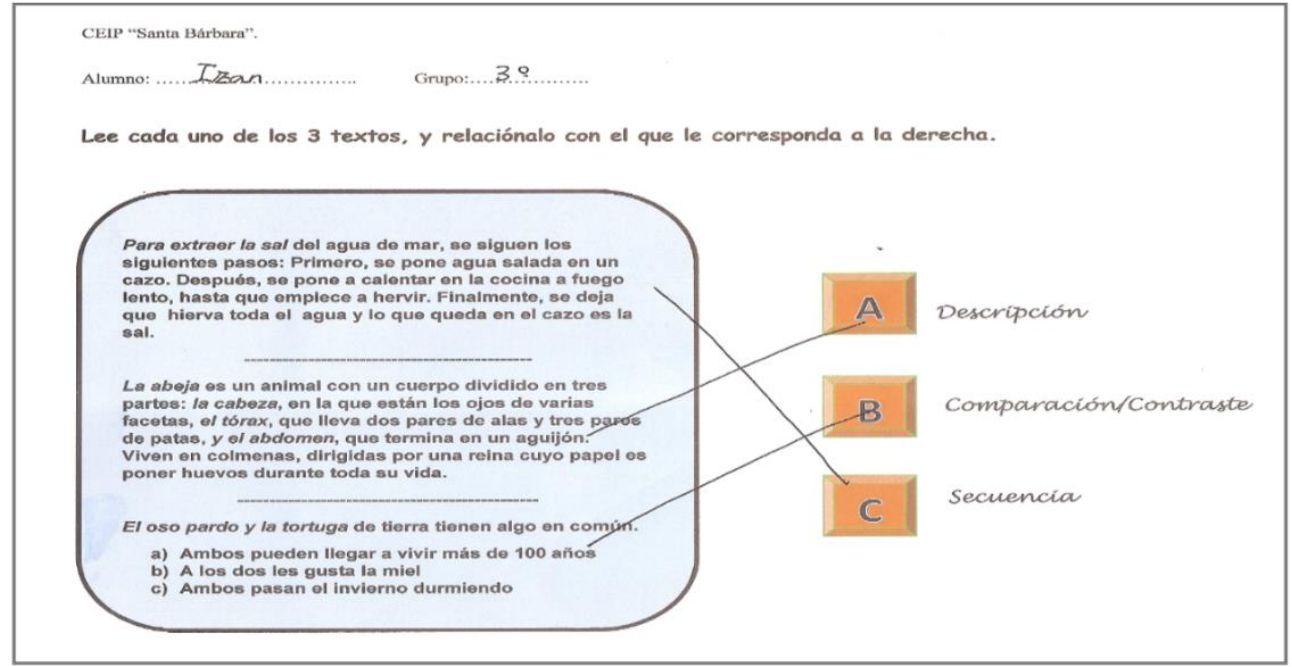

Figura 11. Prueba de reconocimiento de tres estructuras textuales: descripción, comparación/contraste y secuencia

\begin{tabular}{|c|c|c|}
\hline & PRETEST & POSTEST \\
\hline Media & 7,857 & 14,285 \\
\hline Desviación Típica & 2,214 & 3,124 \\
\hline
\end{tabular}

-Kruskal-Wallis chi-cuadrado $=27, d f=11, p=0,004595$

-Wilcoxon Man-Whitney = 9,5, $p=4.754$ e-05

Tabla 2. Datos pretest/postest en media y desviación típica de resultados en Conciencia de Lectura Estratégica

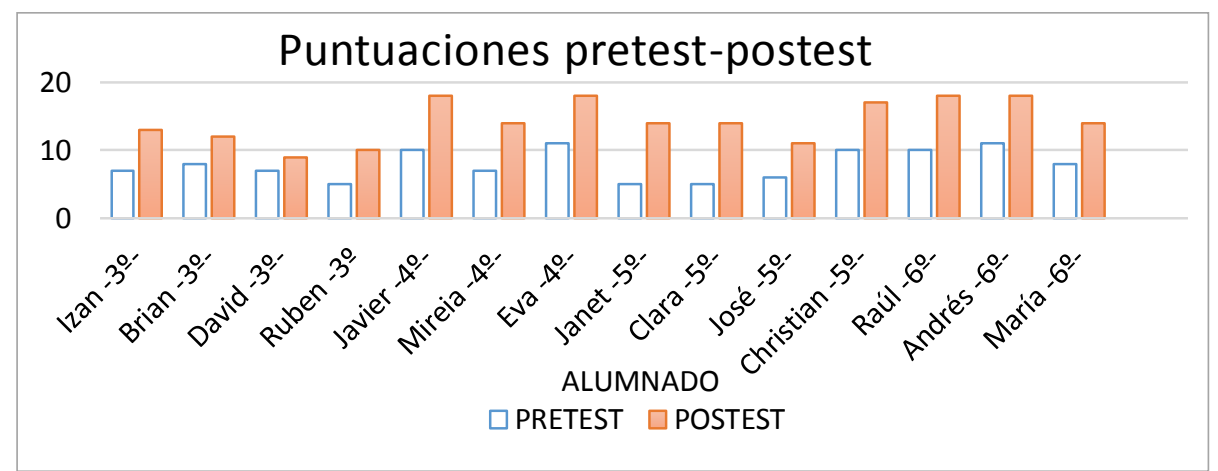

Figura 12. Gráfico de barras pretest/postest en Conciencia de Lectura Estratégica 
Nos interesaba igualmente conocer al final de la experiencia si nuestros alumnos eran ahora más capaces de expresar por escrito frases bien construidas, con algunas de las estructuras trabajadas. En las tablas 3 y 4 se representan los porcentajes de frases bien construidas por los 14 alumnos en la evaluación inicial y en la final, obtenidos en la Prueba de Escritura de Frases bien Estructuradas. Mientras que en septiembre 2013 los porcentajes de estas frases en las tres estructuras analizadas fueron: $25 \%, 11,90 \%$ y $24,43 \%$ respectivamente para el total de alumnos, en junio 2014, esos datos porcentuales se incrementaron hasta el $75 \%$ en frases comparación/contraste, un 64,29\% referidas a la estructura causa/efecto, y un $85,71 \%$ de frases secuenciales. Se observa una mayor dificultad a la hora de expresar por escrito la relación causa/efecto, que hacerlo construyendo frases de comparación/contraste o expresar una secuencia, ésta última la más sencilla. Asimismo, a la derecha de la tabla 4 se recogen en la última columna los datos de la evaluación final de la capacidad del alumnado para reconocer el patrón estructural de cinco textos (ver figura 11). El 65,71\% de esos textos fueron correctamente asignados a una estructura expositiva concreta por los alumnos de $3^{\circ}$ y $4^{\circ}$, subiendo ese dato al $82,86 \%$ en el caso de los estudiantes de $5^{\circ}$ y $6^{\circ}$. Globalmente, los alumnos fueron capaces de reconocer el $74,29 \%$ de esas estructuras textuales.

Finalmente, tras acabar la experiencia, nos planteamos ¿Qué preferencias de lecturas tendrían nuestros alumnos tras estos 8 meses (dos horas a la semana) trabajando con ellos la comprensión de textos informativos? ¿Decidirían leer más textos informativos como una actividad de lectura independiente?

Teníamos claro que apenas existen procedimientos fiables y válidos para conocer el interés, la lógica interna, y las razones que tienen los niños para elegir un tipo de texto sobre otro en Educación Primaria. Por un lado, los clásicos cuestionarios aplicados colectivamente para evaluar el interés por el tipo de lectura de los estudiantes a comienzos del curso escolar son, cuanto menos, escasamente válidos y fiables para el objetivo de averiguar sus preferencias reales y las razones personales de elección de un género literario sobre otro. Curiosamente, se suele plantear que las niñas prefieren la lectura de textos narrativos, y que los niños optan más por textos de naturaleza informativa, particularmente deportes, ciencias e historia. Sin embargo, el predominio de lecturas de textos narrativos sobre los de naturaleza expositiva que tradicionalmente se da en las aulas determina y limita la decisión de muchos niños y niñas por un género literario u otro, o por ninguno si las lecturas con las que están en contacto no se armonizan con sus preferencias o les aburren. En consecuencia, nos planteamos un doble objetivo: a) saber cuáles eran sus preferencias de lectura entre una muestra de libros de naturaleza narrativa y otros informativos, y b) conocer las justificaciones que aportaban a la hora de elegir un libro sobre otros. Para ello, los estudiantes dispusieron de 6 libros expuestos por su portada (3 narrativos y 3 informativos, adaptados a la edad del alumnado) en una mesa del Rincón de Lectura, con el objetivo de que eligieran uno de ellos y las siguientes instrucciones: "Encima de esas mesas hay 6 libros distintos. Cada uno de vosotros tenéis hasta 10 minutos 
para que hojeéis detenidamente cada uno de ellos, y después decidáis cuál es el que más os interesa y os gustaría tener en vuestra casa para leerlo. Solo podéis elegir uno, por lo que deberéis tomaros todo ese tiempo para decidir de entre todos cuál es vuestro favorito. Una vez que lo hayáis decidido, anotáis el título en esta hoja en blanco que os entrego a cada uno, y os sentáis para que otro compañero o compañera pueda levantarse y hacer lo mismo". Globalmente, los resultados muestran que los estudiantes prefirieron más los textos de carácter informativo (el 64\% de las elecciones), frente a los narrativos que fueron elegidos por el $36 \%$ (ver figura 13). Por grupos, los alumnos de tercero y cuarto prefirieron más los textos informativos, que los de quinto y sexto (ver figura14). Además, atendiendo al género (niño/niña), son las niñas las que eligieron de un modo considerable más los libros con contenido informativo (el 80\%), con respecto a los narrativo (un 20\%); mientras que los niños tomaron una decisión más equilibrada (el $56 \%$ de ellos prefirieron los de tipo informativo y el $44 \%$ eligieron los de naturaleza narrativa) (ver figura 15). Considerando ahora el criterio grupo/género, los niños de $3^{\circ}$ y $4^{\circ}$ se decantaron mayoritariamente $(80 \%)$ por los libros informativos mientras que las niñas optaron equilibradamente por ambos géneros de libros $(50 \%)$. Eso no ocurre en $5^{\circ}$ y $6^{\circ}$, donde el $100 \%$ de las niñas escogieron un texto informativo como el género preferido (ver figuras 16 y 17).

Tras la decisión de preferencias de lectura, se pasó a los estudiantes una encuesta individual con 5 preguntas, en la que se les pedía que justificasen su elección y qué acciones habían tomado para decidirse por uno u otro libro. Un análisis de las respuestas a dicha encuesta nos mostró que todos utilizaron pensamiento estratégico para adelantar el contenido del libro, como la observación de la portada, la lectura de la contraportada, la tabla de contenidos, etc.: "Primero miré la portada y la contraportada de todos los libros. A continuación, hojeé un poco los libros y finalmente pensé qué libro me gustaba" (Clara, $5^{\circ}$ curso). Asimismo, el $100 \%$ del alumnado distinguía la naturaleza del texto que eligió: "es un libro informativo porque nos describe cómo son los animales" (Andrés, $6^{\circ}$ curso), y adelantaron una hipótesis: "creo que tratará del Espacio, porque miré la tabla de contenidos" (Eva, 3er curso). Por otra parte, los estudiantes justificaron su elección por el tópico que trataba: "porque me encantan las aves, y es mi cosa favorita y mi pasión. En mi casa tengo un canario, un pájaro salvaje y tres codornices" (José, $5^{\circ}$ curso), "me gusta leer sobre el agua, porque quiero saber cosas del agua" (Miriam, $4^{\circ}$ ). Igualmente, otro alumno justificaba así sus preferencias por unos libros sobre otros: "con los informativos, aprendo y los narrativos me entretienen más, en cambio los informativos me parecen algo aburridos" (Javier, $3^{\circ}$ ). 


\begin{tabular}{|c|c|c|c|c|}
\hline \multicolumn{5}{|c|}{$\begin{array}{c}\text { EVALUACIÓN FINAL. FRASES ESCRITAS BIEN ESTRUCTURADAS } \\
\text { Y RECONOCIMIENTO DE ESTRUCTURAS TEXTUALES }\end{array}$} \\
\hline ALUMNADO & $\begin{array}{l}\text { Comparación / Contraste } \\
\text { Número y porcentaje de frases } \\
\text { escritas bien estructuradas } \\
\text { (Número de frases: } 4 \text {. Número máximo } \\
\text { de frases bien estructuradas: } 28 \text { ) }\end{array}$ & $\begin{array}{l}\text { Causa / Efecto } \\
\text { Número y porcentaje de frases } \\
\text { escritas bien estructuradas } \\
\text { (Número de frases: 3. Número máximo } \\
\text { de frases bien estructuradas: 21) }\end{array}$ & $\begin{array}{l}\text { Secuencia-proceso } \\
\text { Número y porcentaje de frases } \\
\text { escritas bien estructuradas } \\
\text { (Número de frases: } 3 \text {. Número máximo } \\
\text { de frases bien estructuradas: } 21 \text { ) }\end{array}$ & $\begin{array}{c}\text { Reconocimiento de } 5 \\
\text { estructuras textuales tras } \\
\text { leer un texto corto } \\
\text { (número máximo de } \\
\text { aciertos: } 35 \text { ) }\end{array}$ \\
\hline $\begin{array}{l}\text { Curso } 3^{9}-4^{\circ} \\
\text { (7 alumnos) }\end{array}$ & $\begin{array}{c}19 \\
(67,86 \%)\end{array}$ & $\begin{array}{c}12 \\
(57,14 \%)\end{array}$ & $\begin{array}{c}17 \\
(80,95 \%)\end{array}$ & $\begin{array}{c}23 \\
(65,71 \%)\end{array}$ \\
\hline $\begin{array}{l}\text { Curso } 59-6 ? \\
\text { (7 alumnos) }\end{array}$ & $\begin{array}{c}23 \\
(82,14 \%)\end{array}$ & $\begin{array}{c}15 \\
(71,43 \%)\end{array}$ & $\begin{array}{c}19 \\
(90,48 \%)\end{array}$ & $\begin{array}{c}29 \\
(82,86 \%)\end{array}$ \\
\hline $\begin{array}{l}\text { № total de frases } \\
\text { escritas bien } \\
\text { estructuradas } 3^{2}, \\
42,59 \text { y } 62 \\
\text { (14 alumnos) }\end{array}$ & $\begin{array}{c}42 \\
(75 \%) \\
\text { (número máximo de frases bien } \\
\text { estructuradas: 56) }\end{array}$ & $\begin{array}{c}27 \\
(64,29 \%) \\
\text { (número máximo de frases bien } \\
\text { estructuradas: } 42 \text { ) }\end{array}$ & $\begin{array}{c}36 \\
(85,71 \%) \\
\text { (número máximo de frases bien } \\
\text { estructuradas: } 42 \text { ) }\end{array}$ & $\begin{array}{c}\text { TOTAL } \\
52 \\
(74,29 \%) \\
\text { (número máximo de } \\
\text { aciertos: } 70 \text { ) }\end{array}$ \\
\hline
\end{tabular}

Tabla 3. Datos en número y porcentaje de frases escritas bien estructuradas comparación/contraste, causa/efecto y secuencia, en septiembre-2013

\begin{tabular}{|c|c|c|c|}
\hline \multicolumn{4}{|c|}{ EVALUACIÓN INICIAL. FRASES ESCRITAS BIEN ESTRUCTURADAS } \\
\hline ALUMNADO & $\begin{array}{l}\text { Comparación / Contraste } \\
\text { Número y porcentaje de frases } \\
\text { escritas blen estructuradas } \\
\text { (Número de frases: } 4 \text {. Nümero máximo de } \\
\text { frases bien estructuradas: 28) }\end{array}$ & $\begin{array}{l}\text { Causa / Efecto } \\
\text { Número y porcentaje de frases } \\
\text { escritas bien estructuradas } \\
\text { (Número de frases: 3. Número máximo de } \\
\text { frases bien estructuradas: } 21 \text { ) }\end{array}$ & $\begin{array}{l}\text { Secuencia-proceso } \\
\text { Número y porcentaje de frases } \\
\text { escritas bien estructuradas } \\
\text { (Número de frases: 3. . Número máximo de } \\
\text { frases bien estructuradadas: 21) }\end{array}$ \\
\hline $\begin{array}{l}\text { Cursos } 39 \text { Y } 48 \\
\text { (7 alumnos) }\end{array}$ & $\begin{array}{c}5 \\
(17,86 \%)\end{array}$ & $\begin{array}{c}3 \\
(14,29 \%)\end{array}$ & $\begin{array}{c}5 \\
(23,81 \%)\end{array}$ \\
\hline $\begin{array}{l}\text { Cursos } 59 \text { y } 6^{2} \\
\text { (7 alumnnos) }\end{array}$ & $\stackrel{9}{9}$ & $\begin{array}{c}2 \\
(9,52 \%)\end{array}$ & $\begin{array}{c}4 \\
(19,05 \%)\end{array}$ \\
\hline $\begin{array}{l}\text { Total frases escritas bien } \\
\text { estructuradas } 3^{2}, 4^{2}, 5^{2} \text { y } 6^{\circ} \\
\text { (14 alumnos) }\end{array}$ & $\begin{array}{c}14 \\
(25 \%) \\
\text { (número máximo de frases bien } \\
\text { estructuradas: } 56 \text { ) }\end{array}$ & $\begin{array}{c}5 \\
(11,90 \%) \\
\text { (número máximo de frases bien } \\
\text { estructuradas: 42) }\end{array}$ & $\begin{array}{c}9 \\
(21,43 \%) \\
\text { (número máximo de frases bien } \\
\text { estructuradas: 42) }\end{array}$ \\
\hline
\end{tabular}

Tabla 4. Datos en número y porcentaje de frases escritas bien estructuradas comparación/contraste, causa/efecto y secuencia, en junio-2014 


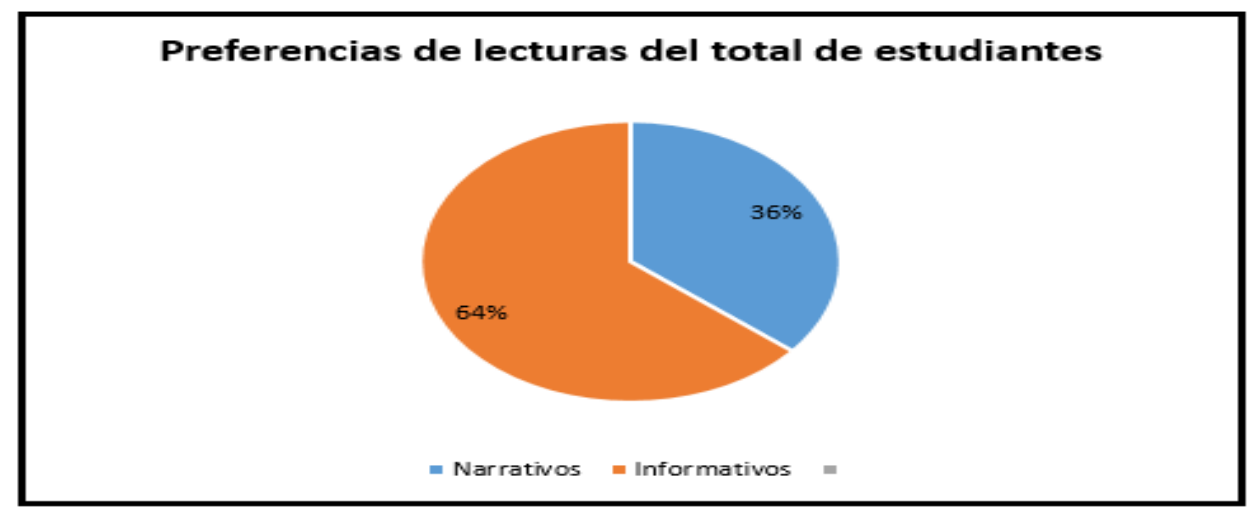

Figura 13. Datos en porcentaje de tipo de texto elegido por los alumnos

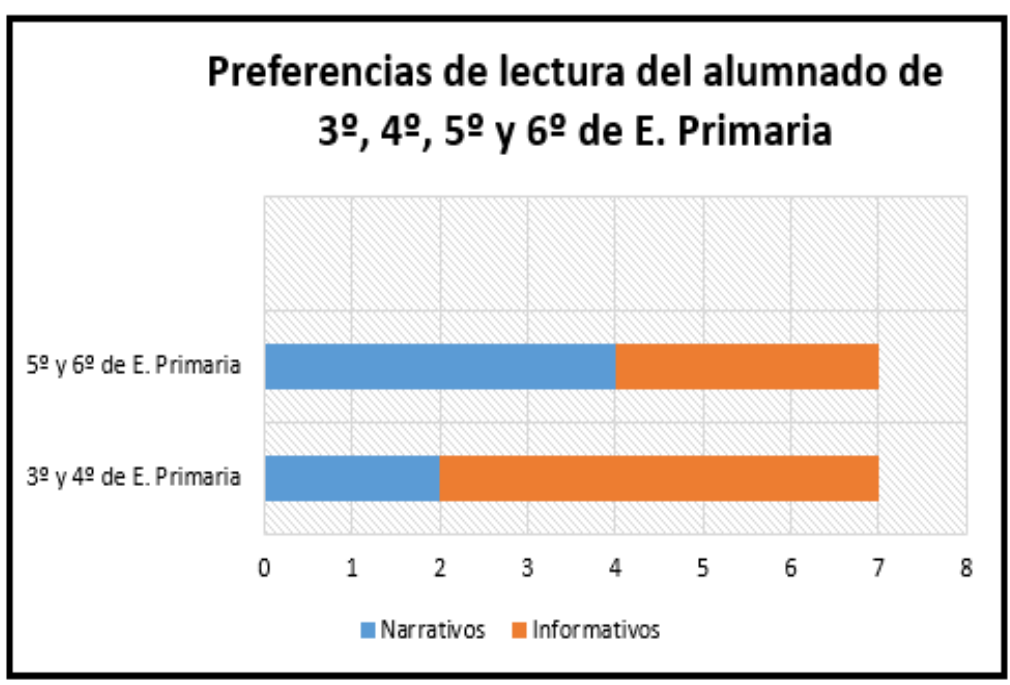

Figura 14. Datos de preferencia del tipo de texto en función del nivel educativo 


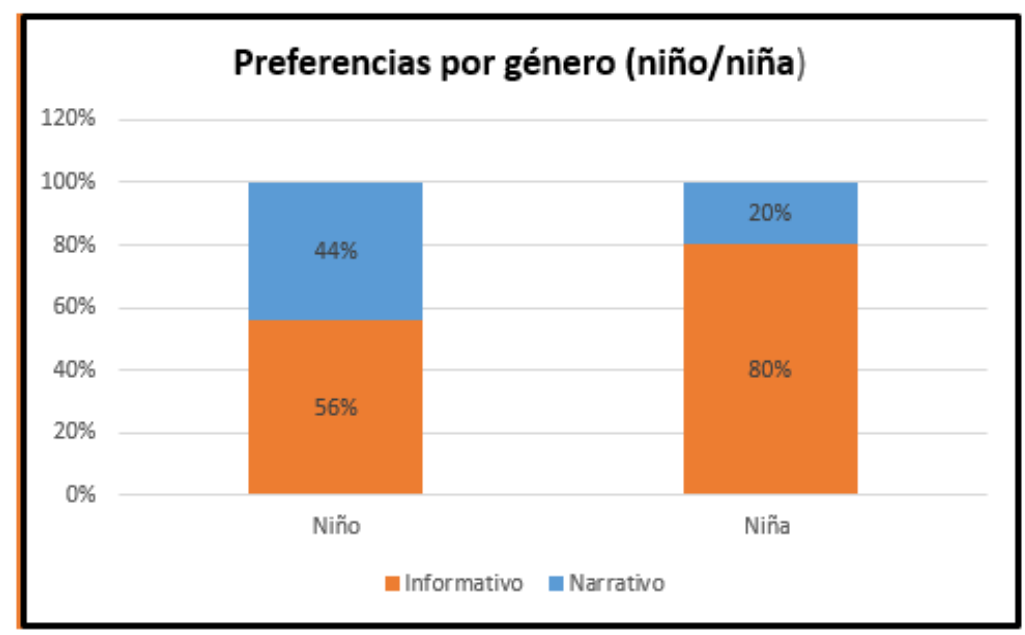

Figura 15. Datos de porcentaje de tipo de texto elegido en función del género (niño/niña) de todo el alumnado

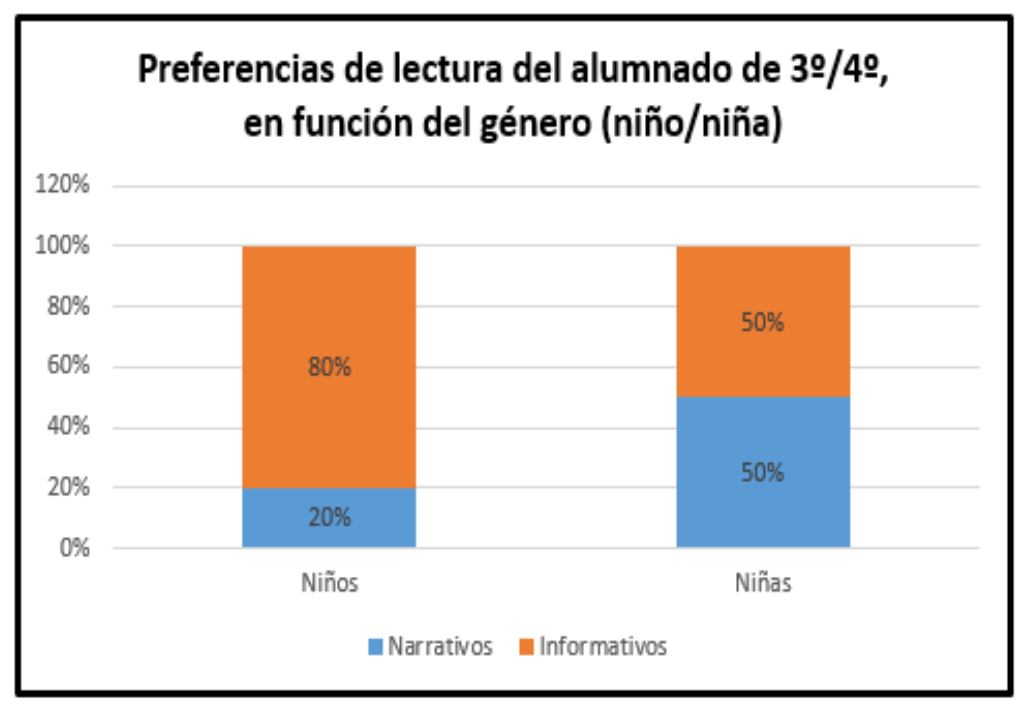

Figura 16. Datos de porcentaje de tipo de texto elegido en función del género (niño/niña) y grupo $\left(3^{\circ} / 4^{\mathrm{a}}\right)$ 


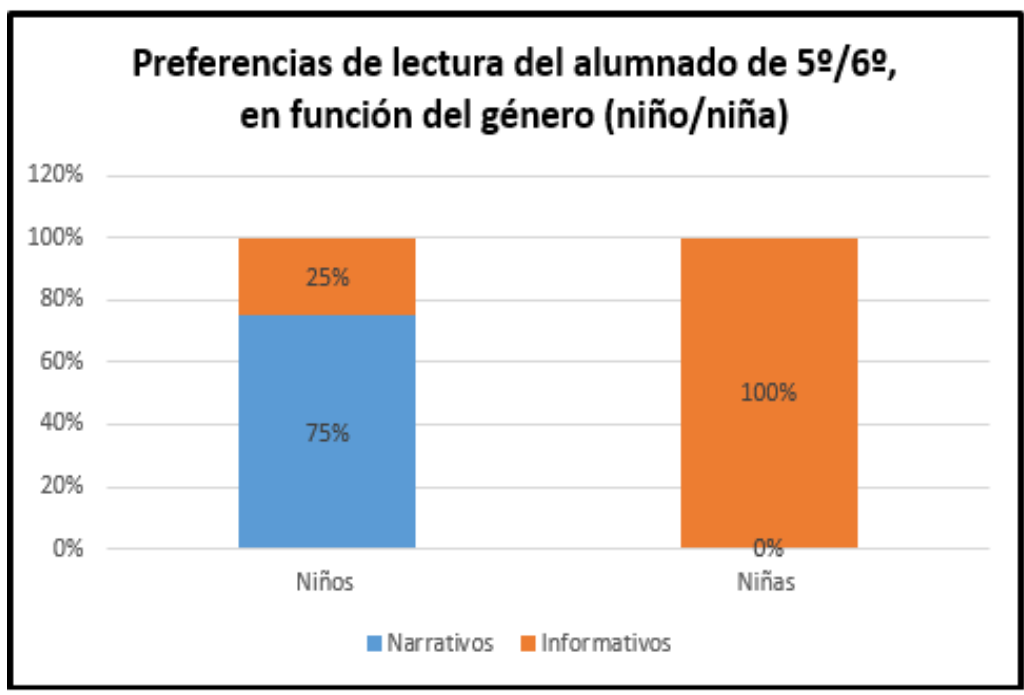

Figura 17. Datos de porcentaje de tipo de texto elegido en función del género (niño/niña) y grupo $\left(5 \% 6^{\mathrm{a}}\right)$

\section{CONCLUSIONES}

La comprensión de textos informativos es difícil para muchos estudiantes y es esencial para el éxito académico, laboral y personal. Sin embargo, mientras que la lectura de textos narrativos es predominante en la escuela, enseñar a comprender los de naturaleza informativa es una carencia pedagógica evidente en la mayoría de aulas de Educación Primaria. La competencia lectora adecuada en un género literario no se transfiere a otro, porque el logro en comprensión es género-dependiente, en el sentido de que el conocimiento de la organización textual representa una condición necesaria para la alfabetización integral del alumnado. En consecuencia, es una labor ineludible de maestros y maestras enseñar a los lectores jóvenes de esta etapa educativa a poner en juego el oportuno pensamiento estratégico específico que requiere la lectura de cada tipo de texto.

Este Proyecto de Innovación Pedagógica constituye una aportación al desarrollo de la comprensión lectora de textos informativos, apoyada en el aprendizaje de su estructura textual. Nuestros alumnos se familiarizaron con determinadas pistas de significado externas e internas de carácter textual y no textual, prestando especial atención a reconocer la variada estructura y modo de organización de las ideas reflejadas en los distintos textos informativos trabajados. A través de un proceso de transferencia gradual desde el docente a los estudiantes en la responsabilidad del uso del necesario pensamiento estratégico para comprender, nuestros catorce alumnos mejoraron de un modo evidente su competencia en la utilización de estrategias cognitivas y metacognitivas de comprensión lectora, sobre las cinco estructuras 
organizativas trabajadas. Especial énfasis se puso en instruirles en el descubrimiento y uso de las palabras-clave que caracterizan la cohesión del texto, así como en habituarlos a que ordenaran sus ideas principales en organizadores gráficos, como esquemas de apoyo visual que les facilitaban posteriormente la elaboración de una representación del texto-base a través de la realización de un resumen escrito bien estructurado.

Los resultados de esta experiencia de innovación nos indican, tal como la investigación educativa actual y el nuevo Currículo de Educación Primaria sugieren, que instruir a los lectores jóvenes en el conocimiento y uso de la estructura textual es una estrategia valiosa de mejora de la comprensión lectora de textos informativos. Asimismo, que el contacto con este tipo textos tiene un efecto positivo en el interés del alumnado por leerlos, tal como lo señalaron nuestros resultados y la opinión de los tutores del CEIP "Santa Bárbara" de Matarrosa, que valoraron positivamente el incremento del nivel de lectura independiente de sus alumnos con estos textos. Finalmente, señalar nuestro deseo de que este trabajo represente una contribución teórico-práctica al debate actual sobre el desarrollo de estándares de aprendizaje de comprensión lectora, y a la revisión de prácticas pedagógicas y materiales de lectura que mejoren la competencia lectora de los estudiantes de Educación Primaria.

\section{BIBLIOGRAFIA}

ÁlVAREZ, Teodoro (2013): Tipos textuales y géneros discursivos. Didáctica del texto en la formación del profesorado, Madrid, Síntesis.

ÁlvAREZ, Teodoro (1996): "El texto expositivo-explicativo", en Didáctica, 8, 29-44. Madrid, Servicio de publicaciones UCM.

ANDERSON, Richard C. \& PEARSON, P. David (1984): "A schema-theoretic view of basic processes in reading comprehension", en P.D. Pearson et al. (eds.), Handbook of reading research 1, New York, Longman, 255-291.

CALERO, Andrés (en prensa, $3^{a}$ edición) Cómo mejorar la comprensión lectora. Estrategias para lograr lectores competentes. Disponible en Web: www.comprension-lectora.org.

CALERO, Andrés, GAMINDE, Ander \& CALERO, Esther (en prensa): Cómo mejorar la comprensión lectora de textos informativos en la educación obligatoria. Disponible en Web: www.comprension-lectora.org.

CASWELL, Linda J. \& DUKE, Nell K. (1998): "Non-narrative as a catalyst for literacy development", en Language Arts, 75, 108-117.

CHALL, Jeanne (1996): Stages of reading development, $2^{\text {nd }}$ edition, Forth Worth, TX: Hartcourt Brace.

DUKE, Nell \& KAYS, Jane (1998): “Can I say 'once upon a time'? Kindergarten children developing knowledge of Information book language", en Early Childhood Research Quarterly, 13, 295-318.

DUKE, Nell K. (2000a): "3.6 minutes per day: The scarcity of informational texts in first grade", en Reading Research Quarterly, 35 (2), 202-224. 
DUKE, Nell K. (2000b): "For the rich it's richer: Print experiences and environments offered to children in very low- and very high-socioeconomic status first-grade classrooms", en American Educational Research Journal, June, 20, (37), 441478.

DUKE, Nell K. (2014): Inside information: Developing powerful readers and writers of informational text through project-based instruction, New York, Scholastics.

DYMOCK, Sue (2009): "Teaching expository text-structure awareness", en Essential Readings on Comprehension, 62-76.

EsCORIZA, José (2006). Estrategias de comprensión del discurso escrito expositivo: evaluación e intervención, Barcelona, Ediciones de la Universidad de Barcelona.

GARCÍA, J. Ricardo, BustOS, Andrea \& SÁNCHEZ, Emilio (2015). "The contribution of knowledge about anaphors, organisational signals and refutations to reading comprehension", en Journal of Research in Reading, 38 (4), 405-427. doi: 10.1111/1467-9817.12021.

GARRALÓN, Ana (2013): Leer y saber. Los libros informativos para niños, Madrid, Tarambana Libros.

HALl-KENYON, Kendra, SABEY, Brenda \& McClellan, Michelle (2005). "Expository text comprehension: Helping primary-grade teachers use expository text to full advantage", en Reading Psychology, 26 (3), 211-23.

HICKS, Devorah (1995): "The social origins of essayist writing", en Bulletin Suisse de Linguistique Appliqué, 61, 61-82.

McNAmARA, Danielle, S. (2004): "Aprender del texto: efectos de la estructura textual y las estrategias del lector", en Revista Signos, 37, 19-30.

MEYER, Bonnie J. (1975): "Identification of the structure of prose and its implication for the study of reading and memory", en Journal of Reading Behaviour, 7, 7-47.

NAGY, William E. (2005). "Why vocabulary instruction needs to be long-term and comprehensive", en E. H. HIEBERT \& M. L. KAMIL (eds.), Teaching and learning vocabulary: Bringing research to practice, Mahwah, NJ, Erlbaum, 27-44.

PAPPAS, Christine C. (1993): "Is narrative primary? Some insights from kindergarteners' pretend readings of stories and information books", en Journal of Reading Behavior, 25, 97-129.

PEARSON, P. David \& DUKE, Nell K. (2002): "Comprehension instruction in the primary grades", en C.C. BLOCK \& M. PRESSLEY (eds.) Comprehension Instruction: Research-based Best Practices, New York, Guilford Press, 247-258.

SANACORE, Joseph \& PALUMBO, Anthony (2009): "Understanding the fourth-grade slump: Our point of view", en The Educational Forum, 73, 67-74.

SNYDER, Lynn \& CACCAMISE, Donna (2010): "Comprehension processes for expository text: Building meaning and making sense", en NIPPOLD, M. \& SCOTT, C. (eds.) Expository Discourse in Children, Adolescents, and Adults, New York, Psychology Press/Taylor \& Francis, 13-40.

YOPP, Ruth H. \& YOPP, Hallie K. (2006): "Informational Texts as Read-Alouds at School and Home", en Journal of Literacy Research, 38 (1), 37-51. 